\title{
ANALISIS VARIASI PANJANG PIPA KAPILER DENGAN SEPARATION CONDENSER TERHADAP PRESTASI MESIN PENDINGIN MENGGUNAKAN DOUBLE EVAPORATOR
}

\author{
Analysis the Length of Capillary Pipe with Separation Condenser on the Performance of \\ Refrigerator using Double Evaporator
}

\author{
Ahmad Adib Rosyadi ${ }^{1}$, William Prizkiabi ${ }^{2}$, Agus Triono ${ }^{3}$ \\ 1,2,3) Program Studi Teknik Mesin, Fakultas Teknik, Universitas Jember \\ Email: ${ }^{1)}$ ahmadadib.teknik.@unej.ac.id, ${ }^{2)}$ willyamprizkiabi@gmail.com, ${ }^{3)}$ agus.triono@unej.ac.id
}

\begin{abstract}
ABSTRAK
Pipa kapiler merupakan alat ekspansi yang umum digunakan pada mesin pendingin. Alat ekspansi termasuk komponen mesin pendingin yang berfungsi menurunkan tekanan refrigerant cair dan mengatur aliran refrigerant menuju evaporator. Penelitian sebelumnya menunjukkan peningkatan COP sebesar 0,6 pada penggunaan panjang pipa kapiler 2,1 meter dibandingkan panjang pipa kapiler 1,5 meter. Penelitian ini menggunakan metode eksperimental dengan membandingkan beberapa jenis variasi antara panjang pipa kapiler 1,5 meter; panjang pipa kapiler 1,8 meter dan panjang pipa kapiler 2,1 meter pada kondensor standar dan kondensor separasi dengan menggunakan double evaporator. Hasil penelitian menunjukkan nilai COP terbesar pada kondensor separasi panjang pipa kapiler 2,1 meter dengan nilai rata-rata 23,66. Kondensor separasi dengan panjang pipa kapiler 2,1 meter dapat meningkatkan nilai COP sebesar 25,72\%.
\end{abstract}

Kata Kunci: pipa kapiler, kondensor separasi, COP, mesin pendingin.

\begin{abstract}
Capillary pipe is type of expansion device commonly used in refrigerators. That is one of the main components of the refrigerator which reduce the pressure of liquid refrigerant and regulate the flow of refrigerant to the evaporator. Last research have shown an increase in COP by 0.6 in the using of 2.1 meter capillary pipe length compared to 1.5 meter capillary pipe length. This research uses an experimental method by comparing several types of variations between 1.5 meter capillary pipe lengths; capillary pipe length of 1.8 meters and length of capillary pipe 2.1 meters with standard condenser and separator condenser by using a double evaporator. The results showed the greatest value of COP in separation condenser of capillary pipe length of 2.1 meters with an average value of 23.66. Separation condenser with 2.1 meter capillary pipe length can increase COP value by $25.72 \%$.
\end{abstract}

Keywords: capillary pipe, separation condenser, COP, refrigerator.

\section{PENDAHULUAN}

Alat pendingin hampir dapat ditemui dengan mudah di sekitar kita pada masa sekarang ini. Penggunaan alat pendingin sendiri dapat ditemukan di berbagai sektor kehidupan masyarakat, seperti rumah tangga, perkantoran, perhotelan dan industri-industri yang ada. Kulkas atau refrigerator menjadi salah satu alat pendingin yang cukup sering kita jumpai. Hampir di setiap rumah tangga memiliki alat tersebut. Refrigerator mempunyai beberapa komponen utama yaitu kompresor, kondensor, evaporator, alat ekspansi, dan refrigerant yang merupakan substansi kerja dalam sistem refrigerasi yang berbentuk fluida (Stoecker dan Jones, 1982:1).

Refrigerant adalah zat yang mengambil panas laten ketika zat menguap dari fasa cair ke gas. Proses pengambilan panas dilakukan pada suhu dan tekanan rendah. Refrigerant mengeluarkan panas laten ketika kondensasi dari fasa gas ke cair pada suhu dan tekanan tinggi. Refrigerant mendinginkan dengan menyerap panas di satu tempat dan mengeluarkannya di tempat lain (Miller dan Miller, 2006:2). Terdapat beberapa jenis refrigerant yang dapat digunakan sebagai substansi kerja, namun beberapa jenis refrigerant memberikan dampak buruk bagi lingkungan jika terjadi kebocoran seperti refrigerant dengan jenis CFC dan HCFC. Penggunaan refrigerant jenis ini sendiri memiliki berbagai macam dampak buruk bagi lingkungan yaitu dapat menimbulkan pemanasan global serta menipisnya lapisan ozon setelah dilakukannya penelitian. Oleh sebab itu mulai digunakan refrigerant yang memiliki sifat ramah lingkungan walaupun performanya tidak sebaik CFC 
dan HCFC, seperti R134a dan LPG. Untuk meningkatkan performa dari alat pendingin dengan refrigerant R134a dan LPG yang memiliki sifat ramah lingkungan, dilakukan berbagai macam penelitian pada komponen utama refrigerator maupun refrigerant itu sendiri.

Tujuan penelitian ini adalah untuk mengetahui bagaimana pengaruh variasi panjang pipa kapiler dengan separation condenser menggunakan double evaporator yang dipasang paralel terhadap dampak refrigerasi, kerja kompresi, kapasitas refrigerasi serta prestasi kerja mesin pendingin.

Kusuma (2015:3) meneliti pengaruh variasi panjang pipa kapiler yang dililitkan pada line suction terhadap prestasi mesin pendingin menggunakan refrigerant LPG. Dari hasil penelitian menggunakan variasi panjang pipa kapiler 1,5 meter, 1,8 meter, dan 2,1 meter dengan LPG sebagai refrigerant dapat diketahui rata-rata nilai COP saat mencapai stabil untuk panjang pipa kapiler 1,5 meter adalah 3,3. Rata-rata nilai COP saat mencapai stabil untuk panjang pipa kapiler 1,8 meter adalah 3,4. Sedangkan rata-rata nilai COP saat mencapai stabil untuk panjang pipa kapiler 2,1 meter adalah 3,9. Dapat disimpulkan bahwa pengaruh penggunaan pipa kapiler pada mesin pendingin dengan panjang 2,1 meter lebih baik dibandingkan panjang pipa kapiler 1,5 meter atau 1,8 meter karena menghasilkan COP (Coeficient Of Performance) terbesar setiap menitnya. Dengan pertambahan panjang pipa kapiler pada mesin pendingin diharapkan dapat meningkatkan nilai COP (Coefficient Of Performance) karena terjadi pendinginan yang lebih cepat. Secara garis besarnya, semakin panjang pipa kapiler maka semakin menurunkan kerja kompresi sehingga meningkatkan nilai COP yang lebih tinggi.

Kondensor separasi adalah kondensor dengan pemisah fasa cair dan pemisah fasa gas. Pada penelitian tentang kondensor separasi didapatkan hasil suhu keluaran yang lebih rendah sebesar 1,3 $\mathrm{K}$ bila dibandingkan dengan kondensor standar. Hasil COP (Coefficient of Performance) pada kondensor separasi dapat meningkat sampai 6,6\% lebih tinggi dari kondensor standar (Li dan Hrnjak, 2017:4). Yahya (2018:5) juga melakukan penelitian tentang unjuk kerja mesin pendingin menggunakan separation condenser dengan penambahan subcooler menggunakan refrigerant LPG. Hasil penelitian ini diperoleh nilai COP tertinggi pada pengujian separation condenser dengan penambahan subcooler pada debit refrigerant 114 x 10-6 m3/s dengan nilai rata-rata sebesar 4,08934. Pada pengujian baseline condenser nilai COP tertinggi pada debit refrigerant $131 \times 10-6 \mathrm{~m} 3 / \mathrm{s}$ dengan nilai COP sebesar 4,22930.

\section{METODE}

Penelitian ini dilakukan dengan menggunakan metode eksperimental dengan variasi jenis kondensor dan panjang pipa kapiler. Jenis kondensor yang digunakan adalah kondensor standar dan kondensor separasi. Panjang pipa kapiler yang digunakan yaitu 1,5; 1,8 dan 2,1 meter. Penelitian ini dilakukan di Laboratorium Konversi Energi II Fakultas Teknik, Universitas Jember.

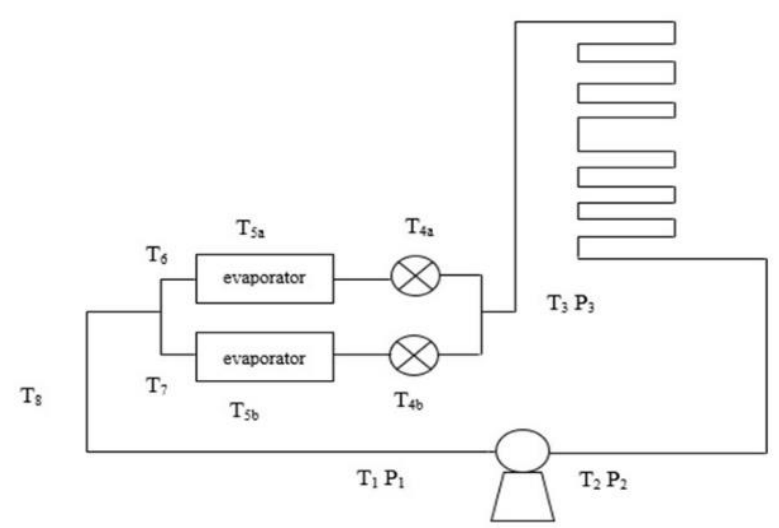

Gambar 1. Rangkaian kondensor standar

Gambar 1. Menunjukkan rangkaian pada kondensor standar dengan 10 titik temperatur dan 3 titik tekanan.

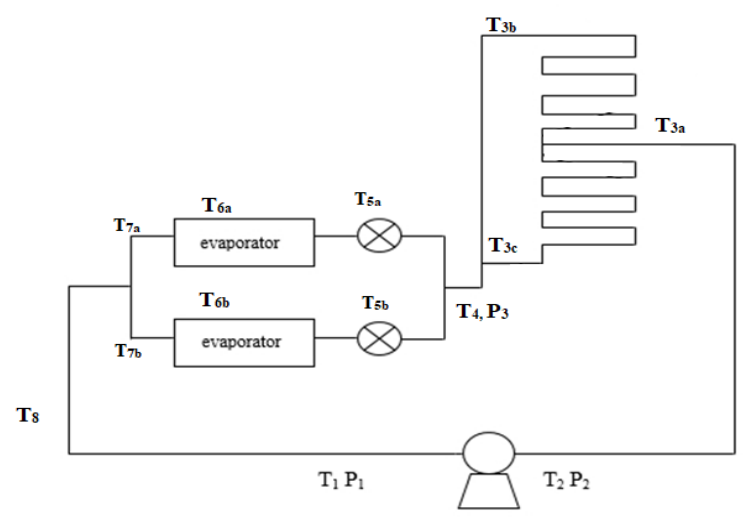

Gambar 2. Rangkaian kondensor separasi 
Gambar 2. Menunjukkan rangkaian kondensor separasi dengan 13 titik temperatur dan 3 titik tekanan.

Alat dan bahan yang digunakan dalam penelitian, antara lain:
a. Dua buah refrigerator
b. Kondensor standar
c. Kondensor separasi
d. Pipa kapiler
e. Manifold dan Pressure gauge
f. Clamp meter
g. Stopwatch
h. Vacuum pump
i. Swaging dan cutting pipe
j. Flame gun dan filler metal
k. Flowmeter
1. R134a
m. Termokopel

Prosedur penelitian:

a. Merangkai komponen alat uji, seperti kompresor, kondensor, kapiler, evaporator serta komponen lainnya dirangkai.

b. Memasang alat ukur amperemeter dan pressure gauge pada beberapa titik yang ditentukan.

c. Mengisi refrigerant R134a.

d. Mencatat semua perubahan temperatur dan tekanan pada setiap titik setiap 15 menit.

e. Mengumpulankan data.

f. Mengolah data menghitung baik secara manual maupun dengan menggunakan aplikasi berupa software coolpack.

g. Menganalisis data.

\section{HASIL DAN PEMBAHASAN}

Data berupa temperatur dan tekanan yang kemudian diolah menjadi entalpi, dari nilai entalpi tersebut didapatkan nilai unjuk kerja mesin pendingin.

\section{a. Dampak Refrigerasi}

Dampak refrigerasi pada Gambar 3 adalah hasil dari selisih nilai entalpi pada keluaran evaporator yang dikurangi dengan nilai entalpi masukan evaporator.

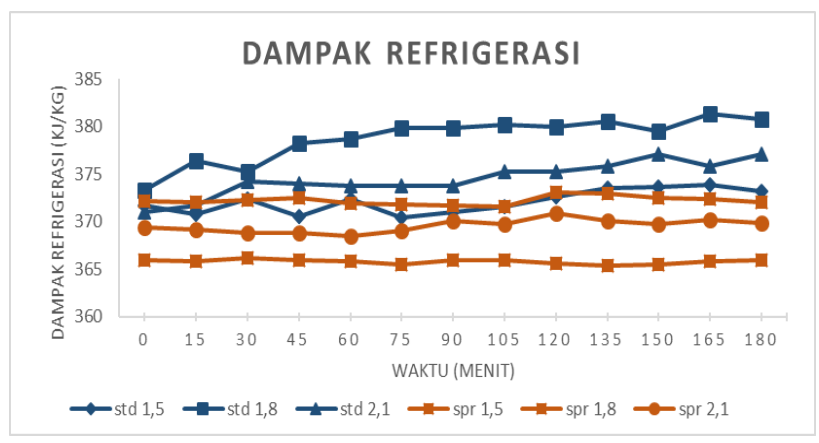

Gambar 3. Hubungan antara waktu (menit) dan dampak refrigerasi $(\mathrm{kJ} / \mathrm{kg})$

Nilai rata-rata dampak refrigerasi yang diperoleh adalah $372,11 \mathrm{~kJ} / \mathrm{kg}$ pada kondensor standar pipa kapiler 1,5 meter; $378,76 \mathrm{~kJ} / \mathrm{kg}$ pada kondensor standar pipa kapiler 1,8 meter; $374,5 \mathrm{~kJ} / \mathrm{kg}$ pada kondensor standar pipa kapiler 2,1 meter; 372,22 $\mathrm{kJ} / \mathrm{kg}$ pada kondensor separasi pipa kapiler 1,5 meter; $365,79 \mathrm{~kJ} / \mathrm{kg}$ pada kondensor separasi pipa kapiler 1,8 meter dan $369,49 \mathrm{~kJ} / \mathrm{kg}$ pada kondensor separasi pipa kapiler 2,1 meter.

Dampak refrigerasi pada kondensor standar pipa kapiler 1,8 meter memiliki nilai rata-rata yang paling tinggi bila dibandingkan dengan panjang pipa kapiler yang lain. Hal ini disebabkan tekanan refrigerant dapat diturunkan optimal dari tekanan kondensasi sehingga refrigerant dapat menyerap kalor pada evaporator dengan suhu dan tekanan yang rendah.

Dampak refrigerasi suatu mesin pendingin mempunyai tren bahwa semakin besar nilai dampak refrigerasi, maka kerja dari mesin pendingin juga semakin baik karena disebabkan dalam siklus refrigerasi tidak terlalu membutuhkan banyak energi untuk menyerap kalor dari lingkungan saat proses evaporasi.

\section{b. Kerja Kompresi}


Kerja kompresi adalah jumlah energi yang dibutuhkan oleh kompresor untuk melakukan siklus refrigerasi selama siklus refrigerasi. Rumus yang digunakan untuk mengetahui nilai dari kerja kompresi adalah selisih antara entalpi keluaran kompresor dengan entalpi masukan kompresor.

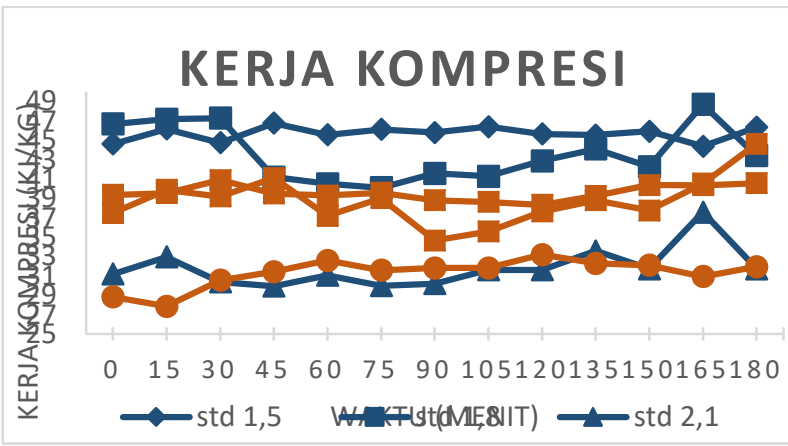

Gambar 4. Hubungan antara waktu (menit) dan kerja kompresi $(\mathrm{kJ} / \mathrm{kg})$

Rata-rata kerja kompresi yang didapatkan dari semua variasi adalah 45,68 kJ/kg pada kondensor standar pipa kapiler 1,5 meter; 42,85 kJ/kg pada kondensor standar pipa kapiler 1,8 meter; $31,81 \mathrm{~kJ} / \mathrm{kg}$ pada kondensor standar pipa kapiler 2,1 meter; 39,56 kJ/kg pada kondensor separasi pipa kapiler 1,5 meter; 38,72 $\mathrm{kJ} / \mathrm{kg}$ pada kondensor separasi pipa kapiler 1,8 meter dan $31,3 \mathrm{~kJ} / \mathrm{kg}$ pada kondensor separasi pipa kapiler 2,1 meter.

Kerja kompresi terendah terdapat pada variasi kondensor separasi pipa kapiler 2,1 meter sebesar 31,3 $\mathrm{kJ} / \mathrm{kg}$. Penggunaan panjang pipa kapiler 2,1 meter menghasilkan kerja kompresi terendah baik pada kondensor standar maupun kondensor separasi bila dibandingkan dengan panjang pipa kapiler lainnya. Hal ini disebabkan penggunaan panjang pipa kapiler 2,1 meter menyebabkan refrigerant pada evaporator dapat menyerap kalor dengan sempurna sehingga refrigerant yang masuk ke kompresor telah berubah fasa menjadi uap sehingga kompresor bekerja dengan ringan dalam mengkompresi refrigerant.

\section{c. Kapasitas Refrigerasi}

Kapasitas refrigerasi merupakan kemampuan untuk mendinginkan ruangan evaporator. Kapasitas refrigerasi dapat diperoleh dari perkalian antara laju aliran massa dengan dampak refrigerasi.

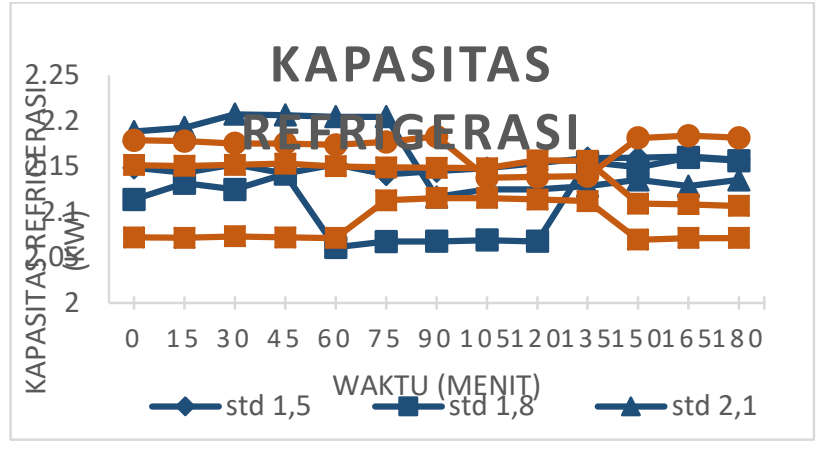

Gambar 5. Hubungan antara waktu (menit) dan kapasitas refrigerasi $(\mathrm{kW})$

Nilai rata-rata kapasitas refrigerasi yang didapatkan adalah 2,15 kW pada kondensor standar pipa kapiler 1,5 meter; 2,112 kW pada kondensor standar pipa kapiler 1,8 meter; 2,161 kW pada kondensor standar pipa kapiler 2,1 meter; 2,141 kW pada kondensor separasi pipa kapiler 1,5 meter; 2,087 kW pada kondensor separasi pipa kapiler 1,8 meter dan 2,169 $\mathrm{kW}$ pada kondensor separasi pipa kapiler 2,1 meter.

Nilai rata-rata kapasitas refrigerasi terbesar terdapat pada kondensor separasi pipa kapiler 2,1 meter. Penggunaan pipa kapiler 2,1 meter memiliki kapasitas refrigerasi paling tinggi baik pada kondensor separasi maupun kondensor standar bila dibandingkan dengan panjang pipa kapiler lainnya. Hal ini disebabkan karena faktor laju alir massa dan dampak refrigerasi yang tinggi.

\section{d. Coefficient of Performance (COP)}

Nilai COP merupakan besaran yang menggambarkan prestasi kerja mesin pendingin. Nilai tersebut dapat diperoleh dengan membandingkan antara dampak refrigerasi dengan kerja kompresi. Semakin tinggi nilai COP menandakan prestasi kerja dari suatu mesin pendingin semakin baik.

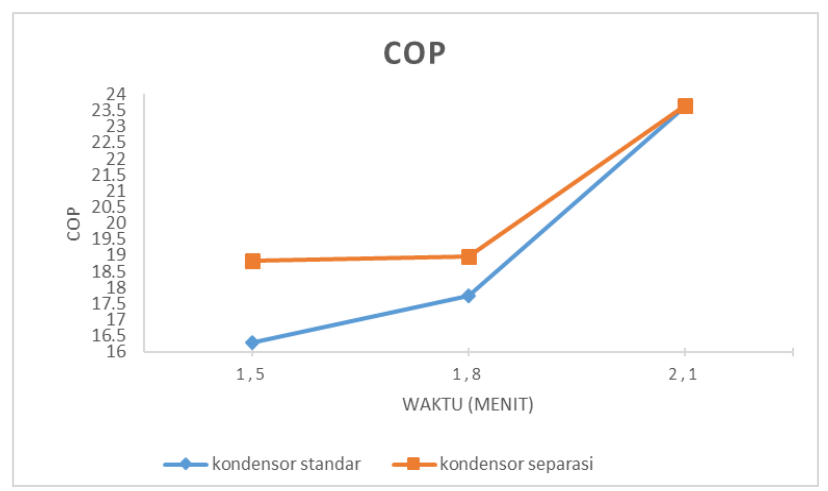


Gambar 6. Hubungan panjang pipa kapiler terhadap nilai Coefficient of Performance

Nilai rata-rata COP yang didapatkan dari penelitian ini adalah 16,29 pada kondensor standar pipa kapiler 1,5 meter; 17,74 pada kondensor standar pipa kapiler 1,8 meter; 23,62 pada kondensor standar pipa kapiler 2,1 meter; 18,82 pada kondensor separasi pipa kapiler 1,5 meter; 18,96 pada kondensor separasi pipa kapiler 1,8 meter dan 23,66 pada kondensor separasi pipa kapiler 2,1 meter.

Penggunaan panjang pipa kapiler 2,1 meter memiliki nilai rata-rata COP paling tinggi bila dibandingkan dengan panjang pipa kapiler lainnya baik pada kondensor standar maupun kondensor separasi. Nilai rata-rata COP tertinggi terdapat pada variasi kondensor separasi pipa kapiler 2,1 meter. Hal ini disebabkan oleh perbandingan nilai dampak refrigerasi dengan kerja kompresi. Pada panjang pipa kapiler 2,1 meter menyebabkan tekanan refrigerant dapat diturunkan optimal dari tekanan kondensasi sehingga refrigerant dapat menyerap kalor pada evaporator dengan suhu dan tekanan yang rendah serta penggunaan panjang pipa kapiler 2,1 meter menyebabkan refrigerant pada evaporator dapat menyerap kalor dengan sempurna sehingga refrigerant yang masuk ke kompresor telah berubah fasa menjadi uap sehingga kompresor bekerja dengan ringan dalam mengkompresi refrigerant.

\section{PENUTUP}

\section{Simpulan}

a. Dampak refrigerasi yang dihasilkan dari penggunaan kondensor standar dengan pipa kapiler 1,8 meter menghasilkan nilai rata-rata dampak refrigerasi tertinggi sebesar $378,76 \mathrm{~kJ} / \mathrm{kg}$. Pada pengujian kondensor separasi menghasilkan nilai rata-rata dampak refrigerasi tertinggi pada panjang pipa kapiler 1,5 meter sebesar 372,22 kJ/kg. Semakin besar dampak refrigerasi maka menandakan jumlah kalor yang diserap oleh evaporator setiap satuan refrigerant juga semakin besar. Bila dibandingkan nilai rata-rata dampak refrigerasi dari kedua kondensor, maka kondensor standar dengan panjang pipa kapiler 1,8 meter menghasilkan nilai dampak refrigerasi terbaik. b. Kerja kompresi pada pengujian kondensor standar dengan panjang pipa kapiler 2,1 meter menghasilkan nilai rata-rata kerja kompresi paling rendah sebesar $31,81 \mathrm{~kJ} / \mathrm{kg}$. Pada pengujian kondensor separasi menghasilkan nilai rata-rata kerja kompresi paling rendah pada panjang pipa kapiler 2,1 meter sebesar $31,3 \mathrm{~kJ} / \mathrm{kg}$. Nilai kerja kompresi kondensor separasi panjang pipa kapiler 2,1 meter menghasilkan nilai rata-rata yang paling rendah dibandingkan kondensor standar pipa kapiler 2,1 meter. Penggunaan variasi panjang pipa kapiler 2,1 meter dapat menurunkan kerja kompresi sehingga kompresor bekerja dengan beban yang ringan dan dapat meningkatkan nilai COP mesin pendingin.

c. Kapasitas refrigerasi pada mesin pendingin dipengaruhi oleh laju aliran massa refrigerant yang digunakan. Kondensor standar pipa kapiler 2,1 meter menghasilkan nilai rata-rata nilai kapasitas refrigerasi tertinggi sebesar 2,161 kW. Pada pengujian kondensor separasi menghasilkan nilai rata-rata kapasitas refrigerasi tertinggi pada panjang pipa kapiler 2,1 meter sebesar 2,169 kW. Nilai ratarata kapasitas refrigerasi panjang pipa kapiler 2,1 meter menghasilkan nilai rata-rata tertinggi bila dibandingkan panjang pipa kapiler lain baik pada kondensor standar maupun separasi. Penggunaan kondensor separasi pipa kapiler 2,1 meter meningkatkan kapasitas refrigerasi sehingga mesin pendingin memiliki kapasitas mendinginkan ruangan yang tinggi setiap laju aliran refrigerant per waktu pada saat melewati evaporator.

d. Berdasarkan hasil penelitian yang dilakukan didapatkan nilai COP tertinggi pada pengujian kondensor separasi pipa kapiler 2,1 meter dengan nilai rata-rata sebesar 23,66. Pada pengujian kondensor standar nilai COP tertinggi pada panjang pipa kapiler 2,1 meter dengan nilai COP sebesar 23,62 . Besarnya nilai COP menjadi nilai ukur sebuah prestasi mesin pendingin, semakin tinggi nilai COP menandakan nilai prestasi mesin pendingin semakin baik. Sehingga variasi kondensor separasi dengan panjang pipa kapiler 2,1 meter dapat dijadikan alternatif untuk meningkatkan performa mesin pendingin dibanding variasi pipa kapiler lain. 


\section{Saran}

Saran yang dapat diberikan oleh peneliti dari hasil penelitian yang telah dilakukan adalah sebagai berikut:

a. Disarankan untuk penelitian selanjutnya mengkaji jenis diameter pipa kapiler serta bentuk geometri pipa kapiler.

b. Disarankan untuk penelitian selanjutnya mengkaji jenis kondensor separasi dengan jumlah pipa u yang tepat.

c. Untuk penelitian selanjutnya disarankan untuk meneliti jenis evaporator untuk mendapatkan unjuk kerja mesin pendingin yang lebih optimal.

\section{DAFTAR PUSTAKA}

[1] Kusuma, D. D. H. 2015. Pengaruh variasi panjang pipa kapiler yang dililitkan pada line suction terhadap prestasi mesin pendingin dengan LPG sebagai refrigeran. Skripsi. Jember: Fakultas Teknik Universitas Jember.

[2] Li, J., dan P. Hrnjak. 2017. Separation in condensers as a way to improve efficiency. International Journal of Refrigeration. 79: 1-9.

[3] Miller, R. dan M. R. Miller. 2006. Air Conditioning and Refrigeration. Singapore: The McGraw-Hill Companies, Inc.

[4] Stoecker, W. F. dan J. W. Jones. 1982. Refrigeration and Air Conditioning. Second Edition. Singapore: McGraw-Hill Inc.

[5] Yahya, A. 2018. Unjuk kerja separation condenser refrigerator dengan penambahan subcooler menggunakan refrigerant liquefied petroleum gas. Skripsi. Jember: Jurusan Teknik Mesin Fakultas Teknik Universitas Jember. 